\title{
Evaluating impact of removable acrylic dentures on oral health related quality of life (OHRQoL) of patients
}

\author{
KHALOUD TARIQ ${ }^{1}$, MAHVISH WAHAD KHAN ${ }^{2}$, UZAIR AHMAD ${ }^{3}$, MUHAMMAD HASSAN ${ }^{4}$ \\ ${ }^{1}$ Assistant Professor, Dept. of Community and Preventive Dentistry, University College of Dentistry, University of Lahore, Pakistan \\ ${ }^{2}$ Postgraduate resident, Dept. of Prosthodontics, Institute of Dentistry, CMH Lahore Medical College, Pakistan \\ ${ }^{3}$ Registrar, Dept. of Prosthodontics, Akhtar Saeed Medical and Dental College, Pakistan \\ ${ }^{4}$ Associate Professor, Dept. of Science of Dental Materials, University College of Dentistry, University of Lahore, Pakistan \\ Corresponding author: Dr. Khaloud Tariq; Email: khaloud.tariq@ucd.uol.edu.pk
}

\begin{abstract}
Objective: To manage patient expectation and provision of relief, it is vital to assess the impact of different domains of oral health associated with denture wearing which affect OHRQoL. Hence, study aimed to evaluate impact of removable acrylic dentures on OHRQoL of patients and assess influence of sociodemographic variables on OHRQoL.

Methods and Material: A cross-sectional study with purposive sampling strategy was used to collect data from denture wearing patients presenting in prosthodontics department of dental teaching hospital of Lahore. A translated version of OHIP-14 (Oral Health Impact Profile) was employed. Mann-Whitney test was used to find association between variables (gender, age, missing teeth, type of denture, denture wearing time) and OHIP-14 items. ANOVA and T-test was performed to evaluate associate between OHIP-14 domain mean and variables.

Results: 206 patients were included in the study. OHIP prevalence was $61.2 \%$, whereas OHIP Score was 19.17 \pm 10.1. Most affected domain was psychological discomfort (mean=1.81) followed by physical pain (1.76) and functional limitation (1.52). Significant association was observed amongst gender with female more likely to have an impact on OHRQoL due to physical disability, functional limitation and physical handicap. Patients with complete dentures were more likely to experience an impact on their OHRQoL due to physical disability and physical pain $(\mathrm{p}=0.04,0.04)$

Conclusions: OHRQoL was satisfactory in our study however, majority of patients experienced problems associated with denture wearing. Most patients experienced psychological discomfort, physical pain and functional limitation. Female gender and patients with more than 5 missing teeth were more likely to have low OHRQoL.
\end{abstract}

Keywords: Oral health, quality of life, dentures

\section{INTRODUCTION}

The etiology of tooth loss is multifactorial; most commonly being associated with carious process and periodontal issues. Such problems themselves are a direct consequence of poor hygiene and eating habits, although systemic disease like Diabetes mellitus can also play a role. Partial or complete tooth loss may severely affect not only oral but physical and mental health of the patient. Research has shown that although people may find wearing dentures acceptable however, loss of tooth leaves a considerable impact on their mental state..$^{1,2}$

Previous literature has emphasized on the adverse effects that can take place due to the loss of teeth such as compromised functional activities like eating and speaking pattern. ${ }^{3}$ With quality of life; specially among older individuals; already being compromised due to the presence of chronic diseases, an impairment in their eating behaviour can interfere with their nutrition further deteriorating health. ${ }^{4}$

Removable prosthesis has been the most common method of replacing missing teeth. However, fixed prosthesis like implant supported dentures are gaining popularity. Nonetheless, it is still seldom executed in a country like Pakistan where affordability of such a prosthesis may alter the treatment plan. While removable dentures have been effectively rehabilitating the patients since long ago, it is not short of problems. Many patients report with post-insertion complaints which affects their quality of life..$^{5}$ Moreover, they may experience loss of retention and support with time due to age related resorption of alveolar bone, which may possibly affect their oral, physical, and psychological well-being. This can result in altered mood, eating habits, and social interaction. ${ }^{6}$ Furthermore, acrylic resin has been known to cause to soreness in mouth resulting in pain and difficulty in eating. ${ }^{7}$ This emphasizes on the importance of gaining knowledge regarding impact of removable acrylic dentures on patient's physical, psychological and social well-being which can help in understanding which aspect of their health is affected more. This will be evaluated through measuring their OHRQoL by employing oral health impacted profile (OHIP-14) instrument. It is a reliable, precise and less timeconsuming instrument which has proven to be valid in different populations. ${ }^{8}$ Hence, the study aimed to assess the influence of removable acrylic dentures on OHRQoL.

\section{METHODS}

This was a cross-sectional survey conducted at a dental teaching hospital of Lahore, Pakistan from September 2018 - September 2019. Purposive sampling was used to collect data from patients. Inclusion criteria comprised of adult consenting patients who were using acrylic partial and complete removable dentures (without metal framework). Patients who couldn't read or understand English or Urdu, had fixed prosthesis or systemic disease like GERD and Diabetes Mellitus were not included in the study. Since accurate statistics regarding denture wearing population is not available, sample size was calculated by evaluating 
number of patients who presented with post insertion complaints in Outpatient Department (OPD) of prosthodontics department in prior 9 months. Calculation was done using online application Raosoft. Total sample size calculated (with estimated population 1045) was 200 with 5\% margin of error, 95\% confidence interval and estimated response of $80 \%$. Ethical review was sought from the Ethical Review Board (ERB) of the university. The study employed a structured questionnaire adopted from standardized Oral Health Impact Profile-14 (OHIP-14) questionnaire. It assesses the perception of impact of oral conditions on patient well-being and measures domains such as functional limitation; physical pain; psychological discomfort; handicap; physical, social, and psychological disability. The responses of the questionnaire are scored between zero and four where $0=$ never, 1 = hardly ever, 2 = occasionally, $3=$ fairly often, and $4=$ very often. After selection of OHIP-14 as a measure of OHRQoL, the questionnaire was validated in Urdu by translation and back-translation and comparing it with the original questionnaire. One Subject specialist and two bilingual researchers were involved in the process. It was then piloted among 30 patients to assess ease of understanding and filling the questionnaire. No issues were raised by respondents hence it was finalized for data collection. 2 researchers were involved in data collection. Participants were assured that no identifiable data was being collected from them and the questionnaire will be kept securely in a locker. Data was entered and analyzed in SPSS 23. Descriptive results are reported as frequencies and percentages. Age was distributed in to 7 categories of 10 year ranging from 20 to 90 years. OHIP prevalence was estimated as number of patients who reported fairly or very often as response to one or more item. OHIP sum was calculated as total sum of responses across domains with scores ranging from $0-56$. Mann-Whitney test used to evaluate relationship between domain items measured on an ordinal scale and variables of age, gender, type of denture, denture wearing time and number of missing teeth. Similarly, independent T-test was applied to observe relation between these variables with mean domain score. ANOVA was used to estimate relationship between age, missing teeth and mean domain score. Statistical significance was defined at $p=0.05$.

\section{RESULTS}

Total of 206 patients participated in the study. Most of the respondents in the sample were male and partial denture wearing patients. Mean age was estimated to be $60.11 \pm$ 13.47 years. $29.6 \%$ (61) of the participants were 61-70 years old, followed by $22.8 \%$ (47) of 51-60 year old's. Majority patients were wearing their prostheses for 1-5 years and had 2-4 missing teeth (35.9\%). OHIP prevalence was estimated to be $61.2 \%$, and OHIP Score was $19.17 \pm$ 10.1. Demographic and denture related characteristics are displayed in table 1.

Table 1: Characteristics of respondents

\begin{tabular}{|l|l|}
\hline Variables & Frequency (\%) \\
\hline Gender & $114(55.3 \%)$ \\
\hline $\begin{array}{l}\text { Male } \\
\text { female }\end{array}$ & $92(44.7 \%)$ \\
\hline Denture type & $63(30.6 \%)$ \\
\hline Complete & $143(69.4 \%)$ \\
Partial & \multicolumn{2}{|l|}{ Denture wearing time } \\
\hline Less than 1 year & $61(29.6 \%)$ \\
1-5 years & $81(39.3 \%)$ \\
6-10 years & $51(24.8 \%)$ \\
More than 10 years & $13(6.3 \%)$ \\
\hline Missing teeth & $26(12.6 \%)$ \\
\hline 1 & $74(35.9 \%)$ \\
$2-4$ & $33(16 \%)$ \\
$5-7$ & $10(4.9 \%)$ \\
$>7$ & $63(30.6 \%)$ \\
All
\end{tabular}

Results of item responses and domain mean are summarized in table 2. As far as the domain of functional limitation was concerned, most participants (55.9\%) reported that they faced problem with pronunciation. As for the domain of physical pain, most participants reported that they felt uncomfortable eating food (56.8\%), and had painful aching in their mouths with dentures (57.8\%). The most problematic aspect was psychological discomfort where $74.8 \%$ participants reported that they felt conscious while wearing dentures. Although, only $43.7 \%$ participants reported feeling tense wearing dentures. Most respondents reported having unsatisfactory diet $(52.4 \%)$ in the domain of physical disability. Least disability was reported in psychological and social aspects. Similar results were observed in domain of handicap. Overall, highest mean was recorded in domain of psychological discomfort, followed by physical pain and functional limitation.

Table 2: Results of Item response of OHIP 14 and domain mean

\begin{tabular}{|c|c|c|c|c|}
\hline OHIP Items & $\begin{array}{l}\text { Never \& Hardly Ever } \\
\mathrm{N}(\%) \\
\end{array}$ & $\begin{array}{l}\text { Occasionally } \\
\mathrm{N}(\%)\end{array}$ & $\begin{array}{l}\text { Fairly \& Quite often } \\
\text { N (\%) }\end{array}$ & $\begin{array}{l}\text { Domain } \\
\text { Mean }\end{array}$ \\
\hline $\begin{array}{l}\text { Functional limitation } \\
\text { Problems with pronunciation } \\
\text { Problems with sense of taste }\end{array}$ & $\begin{array}{l}91(44.2 \%) \\
114(55.3 \%)\end{array}$ & $\begin{array}{l}62(30.1 \%) \\
46(22.3 \%)\end{array}$ & $\begin{array}{l}53(25.8 \%) \\
46(22.3 \%)\end{array}$ & 1.52 \\
\hline $\begin{array}{l}\text { Physical pain } \\
\text { Problems with painful aching } \\
\text { Problems with uncomfortable eating }\end{array}$ & $\begin{array}{l}87(42.2 \%) \\
89(43.2 \%)\end{array}$ & $\begin{array}{l}67(32.5 \%) \\
55(26.7 \%)\end{array}$ & $\begin{array}{l}52(25.2 \%) \\
62(30.1 \%)\end{array}$ & 1.76 \\
\hline $\begin{array}{l}\text { Psychological discomfort } \\
\text { Self-conscious with dentures } \\
\text { Feeling tense with dentures }\end{array}$ & $\begin{array}{l}52(25.2 \%) \\
116(56.3 \%)\end{array}$ & $\begin{array}{l}60(29.1 \%) \\
55(26.7 \%)\end{array}$ & $\begin{array}{l}94(45.7 \%) \\
35(17 \%)\end{array}$ & 1.81 \\
\hline $\begin{array}{l}\text { Physical disability } \\
\text { Problems with unsatisfactory diet } \\
\text { Problems with interrupted meals }\end{array}$ & $\begin{array}{l}98(47.6 \%) \\
131(63.6 \%)\end{array}$ & $\begin{array}{l}57(27.7 \%) \\
45(21.8 \%)\end{array}$ & $\begin{array}{l}51(24.8 \%) \\
30(14.6 \%)\end{array}$ & 1.39 \\
\hline
\end{tabular}




\begin{tabular}{|l|l|l|l|l|}
\hline Psychological disability & $112(54.4 \%)$ & $54(26.2 \%)$ & $40(19.4 \%)$ & $25(12.1 \%)$ \\
Difficulty to relax with dentures & $140(68 \%)$ & $41(19.9 \%)$ & $18(8.8 \%)$ \\
Embarrassment with dentures & $156(75.7 \%)$ & $32(15.5 \%)$ & $25(12.1 \%)$ & $\mathbf{1 . 2 1}$ \\
\hline Social disability & $141(68.4 \%)$ & $40(19.4 \%)$ & & $\mathbf{0 . 9 3}$ \\
\hline Irritable with others & $122(59.2 \%)$ & $42(20.4 \%)$ & $42(20.4 \%)$ & \\
$\quad$ Difficulty doing daily jobs & $160(77.7 \%)$ & $25(12.1 \%)$ & $21(10.2 \%)$ & $\mathbf{0 . 9 8}$ \\
\hline Handicap & \\
Less satisfying life & Total inability to function &
\end{tabular}

Univariate analysis revealed a significant association between gender and functional limitation domain, with females having higher domain mean score as compared to males $(1.74 \pm 1.2$ vs 1.33 $\pm 1.2, p=0.016)$. Similarly, significant association between gender and physical disability domain was also found with a higher mean domain score among females $(1.60 \pm 0.97$ vs 1.21 \pm 1.0 , $\mathrm{p}=0.007)$, psychological disability domain mean score also higher among females ( $1.38 \pm 1.0$ vs $1.07 \pm 1.0, p=0.045)$, and handicap domain mean score also higher for female group as compared to males $(1.15 \pm 1.1$ vs $0.85 \pm 0.9$, $p=0.043)$. Whereas no significant association was found between gender and physical pain, psychological discomfort and social disability.

On the other hand, univariate analysis between age groups and OHIP domains showed a significant association between psychological discomfort, psychological disability and social disability, with higher scores among 20-30 age groups as compared to other age groups $(p=0.042$, $\mathrm{p}=0.050, \mathrm{p}=0.042$ respectively).
No significant association was found between denture wearing time and any of the seven OHIP domains mean score. For denture type, a significant association was found with physical disability, participants with complete denture tend to had higher domain mean score as compared to participants with partial denture $(1.29 \pm 0.93$ vs $1.61 \pm 1.18$, $\mathrm{p}=0.038$ ), similarly physical pain domain mean score was also higher for complete denture as compared to partial denture $(2.00 \pm 1.14$ vs $1.65 \pm 1.08, \mathrm{p}=0.039)$.

Statistical significance was observed with respect to missing teeth and mean of all domains with mean being highest in patients with more than 7 missing teeth and lowest in those missing only one teeth $(p=<0.01)$. Although, in domain of social disability, those with one missing tooth had higher mean as compared to those missing 2-4 teeth $(0.87 \pm 0.95$ vs $0.60 \pm 0.76, p=<0.01)$. Table 3 depicts association of variables with OHIP sum and prevalence.

Table 3: Bivariate analysis showing factors associated with OHRQoL

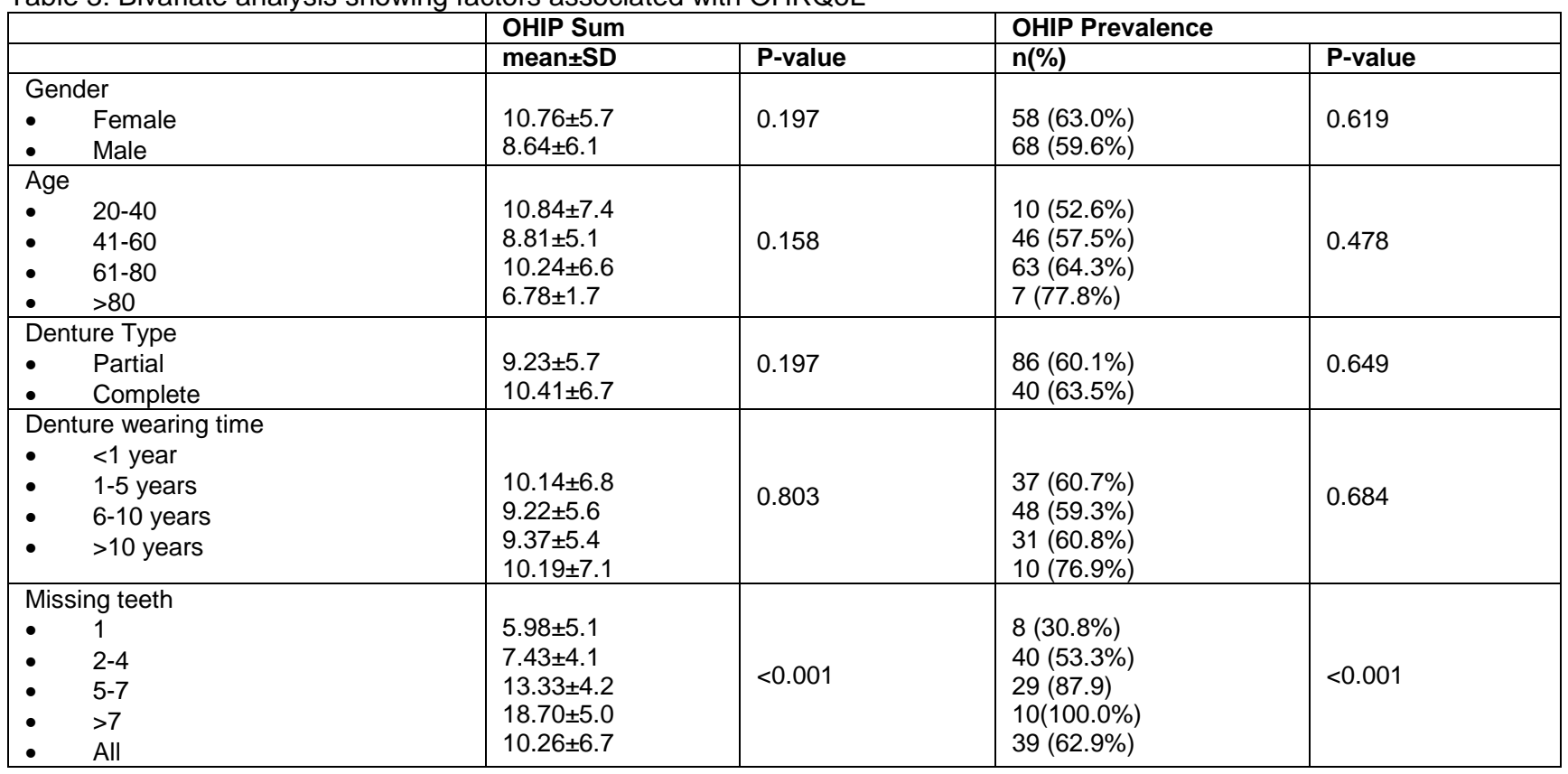

\section{DISCUSSION}

The aim of this study was to assess the impact of removable complete and partial dentures on the oral health quality of life. For a vast majority of people, oral health does have a significant effect on the quality of life as it could impact overall wellbeing of the patient.
The mean age of the respondents in our sample was $60 \pm 13$, meaning majority individuals belonged to the older age group. Having majority of older patients in the sample indicated that most respondents would be more accepting towards their denture's shortcomings. It is possibly because they consider loss of tooth and consequently dentures to be a part of their aging process, which is 
probably why the OHRQoL in our study was satisfactory. This can be corroborated by the fact that OHIP sum was estimated to be $19.17 \pm 10.1$.

A total of $69.4 \%$ respondents reported wearing partial dentures compared to $30.6 \%$ who were reportedly wearing complete dentures. This is probably because partial edentulism is more common than complete edentulism. Most of the respondents in this study had been using dentures for the past 1-5 years followed by those who were using it for less than a year. This shows that most of the participants were in the early phase of adapting to their dentures and that's why they were facing certain problems. A study done by Mayun et al. stated that respondents who were first time removable denture wearers possibly had poor OHRQoL. ${ }^{9}$

OHIP prevalence in this study was found to be $61.2 \%$. In a study by Shaghaghian et al the mean OHIP -14 sum and OHIP -14 prevalence of RPD wearers were 13.80 $( \pm 10.08)$ and $44.5 \%$, respectively. ${ }^{10}$ These scores are comparatively lesser than those observed in our study where the difference could be owing to the fact that our study included both types of removable partial dentures i.e. complete and partial.

In this study, the highest OHIP mean values were observed in domains of psychological discomfort followed by physical pain and functional limitation. This suggest that the patients were conscious and tense with their dentures probably because they were a new addition in the oral cavity and the oral environment was altered owing to them. Also, as more individuals in this study were reportedly wearing partial dentures, their consciousness and tensed feeling could be attributed to the fact that they still had natural teeth in their mouth as a comparison. Correspondingly, they could significantly differentiate between the flawless natural dentition and the newer artificial dentition. Once the patient has lost all teeth the first hand comparison is no longer in their mouth to add to their distress.

In the domain of functional limitation, 55.9\% participant's reported having problems with pronunciation. This could be because of the thickness of acrylic required for its strength which adds to the contour of the palate and makes speech difficult and pronunciation a little muffled. It usually takes several weeks to months at a minimum for the denture wearers to get accustomed to speaking with the dentures. About $44.6 \%$ of respondents complained of variation in their sense of taste. The residual monomer is acrylic resin could be one of the causal factor, as change in taste has been reported as a side effect of these dentures. ${ }^{7}$ In the domain of physical pain, majority reported having an uncomfortable feeling while eating food and painful ache in their mouth. Pain undoubtedly has a negative impact on patient's quality of life; it limits patient's everyday activities and affects involvement in social activities. Thus, it is by far one of the most common problems associated with a dental prosthesis. ${ }^{11,12}$

Least disability was found in psychological and social aspects which means most of the participants neither felt embarrassed nor irritable with their prosthesis. Although, in a study by Modhi Al-Deeb et al., highest score was documented for the functional limitation domain followed by social disability and physical pain. ${ }^{13}$ However, the OHIP mean scores were lowest for psychological discomfort in his study which signified that participants endured with functional difficulty as they didn't cause pain. ${ }^{13}$ The negative oral impacts most experienced comprised of eating $(67.5 \%)$, smiling $(50 \%)$, and emotionally distress $(63.8 \%)$ according to a study by Khan et al. ${ }^{14}$

In the current study demographic variables showed statistical significance in association with OHRQoL whereas in a study done in Indonesia no statistical significance was observed with the demographic variables (gender, age, type of denture). ${ }^{9}$ We found in our study that females were more likely to experience disability in various domains than men. It was also noticed that the problems faced were more significant with increasing age as it could be related to increased irritability, loss of manual dexterity and diminished adaptability with aging. As far as implications of no. of missing teeth are considered, group most affected was those who had 5-7 missing teeth. Those with complete dentures were less likely to be affected as compared to the aforementioned group.

It is imperative that patient's expectations must be taken into account and limitations should be communicated to them so that they are fully aware of adjustments that will have to be made. Also, while few would want restoration of function, some may also be concerned with the esthetic aspect of restoration which can be managed by seeking their input while constructing the prosthesis so that satisfaction is achieved.

The importance of constructing good-quality dentures, educating patients, advocating the need of regular follow up visits as well as continuing ongoing oral care cannot be over-emphasized. All this should be done with the intention of minimizing other oral symptoms and increasing OHRQoL.

\section{REFERENCES}

1. Davis D, Fiske J, Scott B, Radford D. The emotional effects of tooth loss: a preliminary quantitative study. $\mathrm{Br}$ Dent $\mathrm{J}$. 2000; 188:503-6.

2. Saintrain MVL, De Souza EHA. Impact of tooth loss on the quality of life. Gerodontology 2011;29: e632-636.

3. Fiske J, Davis D, Leung K, McMillan A, Scott B. The emotional effects of tooth loss in partially dentate people attending prosthodontic clinics in dental schools in England, Scotland and Hong Kong: a preliminary investigation. Int Dent J. 2001; 51:457e62.

4. Megari K. Quality of Life in Chronic Disease Patients. Health Psychol. Res. 2013;1: e27.

5. Szentpe'tery AG, John MT, Slade GD, Setz JM. Problems reported by patients before and after prosthodontic treatment. Int J Prosthodont 2005; 18:124-31.

6. Knezović-Zlatarić D, Čelebić A, Lazić B. Resorptive changes of maxillary and mandibular bone structures in removable denture wearers. Acta Stomat Croat 2002; 36:261-65. Available from https://core.ac.uk/download/pdf/14378031.pdf

7. Rashid H, Sheikh Z, Vohra F. Allergic effects of the residual monomer used in denture base acrylic resins. Eur $\mathrm{J}$ Dent. 2015; 09:614-19.

8. Almutairi W, Alawad F, Aldosari M, Alshalan A, Alajla K. Oral Health Status and Oral Health-Related Quality of Life (OHRQoL) in Patients with Removable or Fixed Partial Dentures in King Saud Bin Abdulaziz University for Health Sciences (KSAU-HS) Dental Clinics. Int J Med Res Health Sci 2019; 8: 90-100. 
9. Mayun I G, Indrasari M, Kusdhany L. Relationship between patient's satisfaction of removable denture wearers and oral health-related quality of life. Int. J. App. Pharm 2018; 9:150.

10. Shaghaghian S, Taghva M, Abduo J, Bagheri R. Oral healthrelated quality of life of removable partial denture wearers and related factors. J. Oral Rehabil. 2014; 42(1):40-8. Available from https://doi.org/10.1111/joor.12221

11. Palomares T, Montero J, Rosel E, Del-Castillo R, Rosales J. Oral health-related quality of life and masticatory function after conventional prosthetic treatment: A cohort follow-up study. J Prosthet Dent 2018; 119(5):755-63. Available from https://doi.org/10.1016/j.prosdent.2017.07.023

12. Augustin M, Joke D, Bourleyi S, Shenda L, Fidele N, Van T et al. The Effect of Partial Removable Denture Use on Oral
Health Related Quality of Life and Masticatory Function, after 5 Years Use. Open Journal of Stomatology. 2016; 6(10):201-10.

13. Deeb $M$, Abduljabbar $T$, Vohra F, Zafar M, Hussain M. Assessment of factors influencing oral health-related quality of life (OHRQoL) of patients with removable dental prosthesis. Pak J Med Sci 2019;36(2):213-218

14. Khan S, Chikte U, Omar R. Impact of Removable Partial Dental Prostheses on the Oral Health-Related Quality of Life of a South African Cohort with Varied Distributions of Missing Posterior Teeth. J Prosthodont 2017; 28(1): e434e439. Available from https://doi.org/10.1111/jopr.12692 